\title{
Revisitando o conceito de cidadania organizacional: uma nova proposição envolvendo direitos e deveres do trabalhador
}

\section{Revisiting the organizational citizenship concept: a new proposition involving worker rights and duties}

PRICILA DE SOUSA ZARIFE (D)

MARIA DAS GRAÇAS TORRES DA PAZ (D)

\section{RESUMO}

Os termos cidadania organizacional e civismo nas organizações são empregados de forma recorrente na literatura para nomear o mesmo construto. A adoção do termo cidadania organizacional para indicar as ações espontâneas dos trabalhadores não formalmente reconhecidas pela organização, apesar de bastante difundida, tem sido alvo de críticas, visto que etimologicamente cidadania não compartilha deste significado. Diante destas questões, o presente ensaio teórico teve por objetivos discutir a pertinência da adoção dos termos cidadania organizacional e civismo nas organizações, e propor uma definição de cidadania organizacional embasada etimologicamente, envolvendo direitos e deveres do trabalhador na relação com a organização. A proposição de um novo conceito para cidadania organizacional, na perspectiva de direitos e deveres, colabora para a abertura de uma nova linha de investigação e sugere a realização de estudos empíricos para investigar sua relação com outras variáveis, especialmente evidências de validade discriminante com civismo nas organizações.

Palavras-chave: Cidadania organizacional. Civismo nas organizações. Direitos e deveres do trabalhador. 


\section{Abstract}

The terms organizational citizenship and organizational civism are constantly used in literature to designate the same construct. The use of organizational citizenship term to indicate the spontaneous actions of workers not formally recognized by organization, although more widespread, has been criticized, since etymologically citizenship does not share this meaning. In view of these issues, the purposes of this theoretical essay were to discuss the adequacy of the terms organizational citizenship and civism, and to propose a new definition of organizational citizenship based etymologically, involving the rights and duties of the worker in relation to the organization. The proposition of a new concept of organizational citizenship, in the rights and duties approach, contributes to open a new line of research and suggests the realization of empirical studies to investigate its relationship with other variables, especially evidence of discriminant validity with organizational civism.

Keywords: Organizational citizenship. Organizational civism. Worker rights and duties.

\section{INTRODUÇÃo}

A busca por elementos que contribuam para a eficiência e eficácia das organizações se configurou como um dos pilares das investigações em comportamento organizacional. Concentrando-se em como indivíduos, grupos e estruturas impactam o comportamento dos colaboradores, este conhecimento trouxe melhorias aos processos organizacionais (ROBBINS; JUDGE, 2017), além de auxiliar na humanização da gestão das organizações.

Na década de 1980, uma nova linha de pesquisa acerca das ações humanas no ambiente de trabalho se estabeleceu no campo do comportamento organizacional, designada como cidadania organizacional. Tal linha voltou-se especialmente à investigação dos aspectos que levam alguns trabalhadores a irem além das tarefas formalmente prescritas em seu trabalho, enquanto outros ficam restritos a estes limites (GOMES et al., 2014).

As discussões iniciais sobre a cidadania organizacional associaram o termo às ações espontâneas e informais dos trabalhadores, 
balizando-o como de suma importância para o sucesso da organização. Desde então, um fluxo crescente de pesquisas vem sendo desenvolvido alicerçado nesta perspectiva, no início interessado especialmente no nível individual de análise, e, mais recentemente, estendido aos níveis grupal e/ou da unidade organizacional (PODSAKOFF et al., 2014).

Ocorre que o termo cidadania organizacional vem recebendo críticas acerca de suas limitações para nomear tais ações espontâneas, ao passo que em sua essência tal vocábulo envolveria gozo de direitos e sujeição à autoridade. Tal constatação culminou na proposição de uso do termo civismo nas organizações, haja vista que seu significado seria mais congruente com os comportamentos espontâneos supracitados (SIQUEIRA, 1995; PORTO; TAMAYO, 2003).

Todavia, a literatura e a prática profissional ainda são predominantemente marcadas pelo uso do termo cidadania organizacional, muitas vezes considerado equivalente ao civismo nas organizações (DIAS; OLIVEIRA, 2016). Este equívoco denota certa confusão conceitual que pode ter como aspecto basilar a lacuna acerca de uma real definição de cidadania no contexto organizacional: enquanto certas apreciações indicaram uma maior pertinência do termo civismo nas organizações para abarcar as ações espontâneas e informais dos trabalhadores, nenhuma perspectiva foi proposta rumo a um conceito etimologicamente adequado para o termo cidadania organizacional.

Diante disso, fica clara a necessidade de promoção e realização de discussões mais acuradas sobre os construtos, de modo a auxiliar na distinção dos termos cidadania organizacional e civismo nas organizações e, por conseguinte, minimizar a confusão conceitual que tem seus reflexos também na prática profissional. $O$ presente ensaio teórico teve como objetivos discutir a adequação da adoção dos termos cidadania organizacional e civismo nas organizações, e propor uma nova definição para cidadania organizacional embasada etimologicamente.

\section{BREVE HISTÓRICO DO CONSTRUTO CIDADANIA ORGANIZACIONAL}

Na primeira metade do século passado, Chester Barnard (1938) propôs sua teoria sobre a cooperação nas organizações formais. Ao defender que a disposição dos trabalhadores para realizar esforços 
cooperativos era essencial para a existência, sobrevivência e efetividade da organização, este autor acabou por fincar as raízes que tempos depois viriam a embasar as ideias sobre cidadania organizacional.

As proposições de Barnard (1938), indicando que o sistema organizacional necessita da vontade de cooperar dos trabalhadores, foram revisitadas por Katz e Kahn (1974) ao introduzirem o termo "cidadão organizacional" para representar os comportamentos espontâneos do trabalhador que ultrapassam o que está previsto para sua função na organização. Para eles, estes comportamentos não prescritos formalmente e elementares para a sobrevivência e efetividade das organizações poderiam ser classificados em cinco categorias: cooperar com os colegas de trabalho, proteger o sistema organizacional, oferecer sugestões criativas para a organização, buscar autotreinamento para maior responsabilidade na organização e criar um clima externo favorável à organização. Com a proposição destas categorias, pode-se afirmar que estes autores propuseram a primeira definição operacional do construto cidadania organizacional.

Outro importante trabalho para o desenvolvimento das ideias sobre cidadania organizacional, foi publicado por Organ (1977) ao refutar o entendimento da época de que a relação entre satisfação no trabalho e desempenho não era significativa. Para tanto, ele propôs uma distinção entre aspectos quantitativos e qualitativos do desempenho, incluindo na segunda categoria os comportamentos com efeitos positivos sobre os contextos psicológico, social e organizacional (SPITZMULLER; DYNE; ILIES, 2008). Na tentativa inicial de incluir esses comportamentos como representação de desempenho, defendeu que satisfação no trabalho provavelmente estaria relacionada a aspectos de desempenho que iriam além das exigências formais (ORGAN, 1988).

Alicerçados nas noções de vontade de cooperar dos trabalhadores (BARNARD, 1938) e comportamentos espontâneos não previstos formalmente (KATZ; KAHN, 1974), na década seguinte tais comportamentos foram nomeados formalmente como comportamentos de cidadania organizacional (CCO), por Bateman e Organ (1983), juntamente com o fornecimento do suporte empírico para a relação entre satisfação e cidadania (desempenho qualitativo). Vale atentar que Katz e Kahn (1974) não mencionaram em seu trabalho inicial o 
termo cidadania organizacional, tendo discorrido exclusivamente acerca das características do cidadão organizacional.

Desde sua proposição, vários estudos foram realizados e definições apresentadas com vistas a abarcar o construto. Uma definição clássica para CCO foi apresentada por Organ (1988, p.4), enquanto “comportamentos discricionários, não direta ou explicitamente reconhecidos pelo sistema de recompensa formal, e que, no conjunto, promovem o funcionamento eficaz da organização".

Mais especificamente, os CCO seriam aqueles comportamentos que não fazem parte das funções formais dos colaboradores, mas que contribuem para a conquista de bons resultados organizacionais, apesar de não serem formalmente recompensados. Assim, é necessário que os trabalhadores vão além da simples observância das normas e dos regulamentos explícitos para que a organização obtenha ganhos em efetividade.

O interesse pelo estudo da cidadania organizacional vem crescendo substancialmente desde a década de 1980 (PODSAKOFF et al., 2014). Um levantamento da literatura internacional, considerando os anos de 1983 a 2017, indicou que aproximadamente 83\% dos artigos publicados sobre cidadania organizacional e construtos relacionados correspondem aos últimos dez anos investigados. Ainda cabe destacar que algumas das publicações acadêmicas internacionais com maiores índices de citação nas áreas de Gestão de Negócios e Psicologia Organizacional e do Trabalho têm como foco cidadania organizacional (PODSAKOFF, P.; MACKENZIE; PODSAKOFF, N., 2018).

Enquanto os estudos iniciais sobre o tema se voltaram, especialmente, ao exame dos antecedentes do CCO, identificando diferenças individuais, variáveis atitudinais, de liderança e características do trabalho (ORGAN; PODSAKOFF; MACKENZIE, 2006), com a evolução da literatura da área, as investigações passaram a considerar o exame dos efeitos do CCO nos resultados do indivíduo e das organizações (PODSAKOFF et al., 2014). Isto posto, deu-se o reconhecimento de que se trata de uma relevante variável critério do ambiente organizacional, contribuindo especialmente para a sobrevivência e o alcance da efetividade organizacional (PORTO; TAMAYO, 2003; PODSAKOFF et al., 2014). 
A despeito dos esforços dos pesquisadores, envolvendo especialmente a proposição de instrumentos, a investigação da dimensionalidade do construto e o exame de uma ampla gama de fatores preditivos e critérios, não há consenso acerca da dimensionalidade da cidadania organizacional (GOMES et al., 2014). Ocorre que diferentes modelos foram propostos, dentre eles: (1) unidimensional (BATEMAN; ORGAN, 1983); (2) bidimensional - altruísmo e complacência/obediência generalizada (SMITH; ORGAN; NEAR, 1983); (3) pentadimensional - versões distintas apresentadas na literatura (PODSAKOFF et al., 1990; SIQUEIRA, 1995; PORTO; TAMAYO, 2003).

Juntamente com a proposição inicial do termo, Bateman e Organ (1983) apresentaram um instrumento unidimensional, composto por 30 itens, escala de resposta de 7 pontos e bons índices de confiabilidade $(\alpha>0,90)$. No mesmo ano, Smith, Organ e Near (1983) apresentaram uma medida para o construto, com 16 itens, numa escala tipo likert, distribuídos em duas dimensões: (1) altruísmo comportamento direta e intencionalmente destinado a ajudar uma pessoa específica em situação face-a-face $(\alpha=0,88)$; (2) complacência/ obediência generalizada - atinente à ajuda indiretamente útil para outras pessoas envolvidas no sistema $(\alpha=0,85)$. Investigando antecedentes do $\mathrm{CCO}$, eles encontraram os seguintes resultados: (1) a satisfação no trabalho, medida como estado de humor crônico, mostrou um caminho preditivo direto apenas para a dimensão altruísmo; (2) suporte do líder influenciou indiretamente o altruísmo, através de seu efeito sobre a satisfação; (3) suporte do líder mostrou um efeito direto sobre complacência/obediência generalizada; (4) interdependência da tarefa e medidas de personalidade não apresentaram efeitos diretos ou indiretos.

A revisão da literatura nacional mais recente, realizada por Zarife (2016), indicou que, entre os anos 2000 e 2015, a maioria dos estudos publicados no Brasil investigando o construto adotou a perspectiva pentadimensional do instrumento desenvolvido por Porto e Tamayo (2003). Trata-se de uma escala cujas dimensões são as cinco categorias de comportamento propostas por Katz e Kahn (1974): criação de clima favorável à organização no ambiente externo $(\alpha=0,90)$; sugestões criativas ao sistema $(\alpha=0,91)$; proteção ao 
sistema $(\alpha=0,80)$; autotreinamento $(\alpha=0,84)$; cooperação com colegas de trabalho $(\alpha=0,85)$.

Corroborando a complexidade acerca das dimensões do construto, numa revisão de literatura internacional, Podsakoff et al. (2000) identificaram quase 30 diferentes formas de conceituação de cidadania, que foram agrupadas em sete grandes vertentes: (1) comportamento de ajuda; (2) espírito esportivo; (3) lealdade organizacional; (4) complacência organizacional; (5) iniciativa individual, (6) virtude cívica; e (7) autodesenvolvimento. Eles identificaram ainda um aumento expressivo do número de publicações internacionais sobre o tema, comparando períodos das décadas de 1980 e 1990: 13 artigos entre 1983 e 1988 e 122 entre 1993 e 1998. Lembrando que o primeiro período abarca os anos iniciais da proposição do construto.

Uma revisão da literatura internacional foi realizada por Costa e Andrade (2015), envolvendo artigos sobre o tema publicados entre 2002 e 2012, nos nove principais periódicos internacionais de Psicologia e de Administração. Os resultados indicaram que: (1) foram encontrados 148 artigos sobre cidadania, dentre eles, 118 empíricos; (2) a maioria dos autores pertence a universidades norte-americanas; (3) a maior concentração de artigos ocorreu em 2010 e 2011; (4) a maioria dos estudos empíricos investigaram a relação entre cidadania e justiça organizacional $(18,64 \%)$, liderança $(14,41 \%)$, desempenho no trabalho e nas tarefas $(10,17 \%)$, satisfação no trabalho $(10,17 \%)$ e comprometimento organizacional $(8,47 \%)$, indicativo de que sejam importantes antecedentes do construto.

Como é possível constatar, desde sua proposição, o termo cidadania organizacional vem sendo bastante disseminado na literatura, convertendo-se em um relevante construto para as áreas de Gestão e Psicologia (PODSAKOFF et al., 2000; PODSAKOFF et al., 2014; PODSAKOFF, P.; MACKENZIE; PODSAKOFF, N., 2018). Apesar de sua popularidade, o construto e sua designação não estão isentos de críticas, especialmente acerca de sua pertinência para denominar e retratar os comportamentos espontâneos dos colaboradores para a organização (SIQUEIRA, 1995; PORTO; TAMAYO, 2003; DIAS; OLIVEIRA, 2016; TINTI, COSTA; VIEIRA; CAPPELLOZZA, 2017). Diante desta constatação, o primeiro objetivo do presente ensaio 
teórico foi discutir os termos cidadania organizacional e civismo nas organizações, o substituto proposto na literatura.

\section{Cidadania organizacional ou Civismo? Discutindo a ADEQUAÇÃO DOS TERMOS COM BASE NA ETIMOLOGIA}

Não obstante ao grande interesse pelo construto, a literatura de cidadania organizacional é caracterizada pela dificuldade de conceituação e, consequentemente, por problemas no que tange à delimitação teórica e dimensionalidade (GOMES et al., 2014). Parte do debate acerca da pertinência da definição envolvendo os comportamentos espontâneos, decorre da própria complexidade em conceituar adequadamente a cidadania no âmbito geral, não apenas no contexto das organizações.

Embora o termo cidadania se configure enquanto elemento fulcral na agenda intelectual e política das sociedades atuais, não há um entendimento consensual em torno de seu significado e sua história (BOTELHO; SCHWARCZ, 2012). É possível identificar uma profusão de conceitos sobre cidadania na literatura, tornando complexa a opção por um que possua abrangência suficiente para aplicações em qualquer lugar ou situação.

Isto ocorre, possivelmente, por este conceito estar ligado justamente à evolução histórica das sociedades, renovando-se constantemente frente às transformações sociais e de paradigmas ideológicos (REZENDE FILHO; CÂMARA NETO, 2001; LIMA; MENEZES JUNIOR; BRZEZINSKI, 2017). A cidadania não é uma ideia estática, mas dinâmica/histórica, acarretando que seu sentido varia no tempo e no espaço, e que ser cidadão pode ter diferentes implicações a depender do país em que se encontre (BOTELHO; SCHWARCZ, 2012; PINSKY, 2013).

A palavra cidadania vem do latim civitas, atinente ao indivíduo que habita a cidade, remetendo uma comunidade politicamente organizada (GORCZEVSKI; MARTIN, 2011; BOTELHO; SCHWARCZ, 2012; PELLENZ, 2017). Tradicionalmente, a origem da cidadania remonta à Antiguidade, possivelmente ao desenvolvimento das polis gregas, quando teve seu significado associado à liberdade, igualdade e às virtudes republicanas (BOTELHO; SCHWARCZ, 2012). 
Neste período, ser considerado cidadão ia além de habitar um local: envolvia a possibilidade de desfrutar de todos os direitos políticos. Para tanto, era necessário ser homem adulto, nascido em terras gregas, cujo pai também tivesse sido cidadão (GORCZEVSKI; MARTIN, 2011). Assim, os escravos, os estrangeiros, as mulheres e as crianças não atendiam a estes critérios e eram, portanto, desconsiderados neste contexto (PELLENZ, 2017).

Com o tempo, a noção de cidadania como estritamente ligada à origem e aos laços consanguíneos foi ruindo, tornando-se mais ampla. Houve redistribuição do poder político e, por conseguinte, a aceitação do acesso de estrangeiros à categoria de cidadão, modificando-se o conceito de cidadania, apesar de seu significado ainda remeter à participação política.

Durante a Idade Média, houve uma perda do significado de cidadania como concebida na Antiguidade. Nesse período, questões políticas, fragilizadas, perderam espaço para instituições religiosas que passaram a ser responsáveis pelos registros civis, pela educação e orientação cívica e espiritual (REZENDE FILHO; CÂMARA NETO, 2001; GORCZEVSKI; MARTIN, 2011; PELLENZ, 2017). Apesar de não adotar o termo, o significado conferido à cidadania neste período histórico envolvia ser homem cristão que possuía vínculo, enquanto subordinado, com uma diocese (GORCZEVSKI; MARTIN, 2011).

No Estado Moderno, havia o soberano (acima das leis e definido pela hereditariedade) e os cidadãos (súditos livres que lhe deviam obediência). Assim, não eram os privilégios que denotavam cidadania: ser cidadão compreendia dever obediência e submissão ao poder (GORCZEVSKI; MARTIN, 2011), aludindo apenas aos deveres, sem envolver direitos.

Com as mudanças sociais e as lutas por igualdade e liberdade como princípios básicos, a sociedade hierarquizada baseada em privilégios decorrentes do nascimento, e toda a desigualdade resultante (até então concebida como vontade divina), foram severamente questionadas, perdendo força. Estes tempos estimularam o desejo de obter direitos (MONDAINI, 2013). Assim, se dantes a cidadania era alicerçada nos deveres dos súditos, as drásticas transformações sociais e culturais da época ocasionaram nova modificação na con- 
cepção vigente de cidadania, alicerçando-a nos direitos do cidadão (PELLENZ, 2017).

Apesar da pluralidade de acepções que pode ser atribuída à cidadania, na atualidade, seus numerosos significados convergem, em um sentido amplo, rumo a um conjunto de valores e práticas dos deveres e do reconhecimento de direitos. O entendimento mais comum de ser cidadão envolve "fazer parte de um todo maior, modernamente identificado a uma nação ou comunidade política específica, e ter direitos garantidos pelo Estado, com o qual temos também deveres" (BOTELHO; SCHWARCZ, 2012, p. 11).

A noção de cidadania determina a forma como os indivíduos se relacionam com a comunidade política, constituindo o reconhecimento do acesso aos direitos e deveres compartilhados pelos cidadãos na sociedade (GORCZEVSKI; MARTIN, 2011). Os debates dão um caráter reivindicatório à cidadania, onde é sabido que um cidadão deve atuar em benefício da sociedade, e esta deve garantir-lhe direitos básicos à vida, como moradia, educação e saúde. Esta noção confere à cidadania um significado alusivo ao relacionamento entre uma sociedade e seus membros/cidadãos (REZENDE FILHO; CÂMARA NETO, 2001), deixando de restringi-la à participação política.

De acordo com o Dicionário de Ciências Sociais (SILVA, 1986, p. 177), com base numa relação de troca entre pessoa e Estado, cidadania diz respeito ao "estatuto oriundo do relacionamento existente entre uma pessoa natural e uma sociedade política, conhecida como o Estado, pelo qual (o estatuto) a pessoa deve a este obediência e a sociedade lhe deve proteção. Esse estatuto, nascido de um relacionamento entre o indivíduo e o Estado, é determinado pela lei do país e reconhecido pelo direito internacional".

$\mathrm{O}$ exposto reforça que a cidadania se constitui um processo em permanente construção, ao passo que envolve uma conquista política, aplicada no cotidiano (PELLENZ, 2017), modificando-se ao longo dos séculos e em cada país. O que resulta numa abertura maior ou menor do estatuto de cidadão para a população (como a inclusão de imigrantes à cidadania), grau de participação política de diferentes grupos (o voto da mulher) e direitos sociais (PINSKY, 2013).

Porto e Tamayo (2003) pontuaram que o termo cidadania denota tanto submissão à autoridade quanto o exercício do direito. 
Em consonância, a definição proposta pelo Dicionário Houaiss da Língua Portuguesa (HOUAISS, 2001, p. 553) considera cidadão o "indivíduo que, como membro de um Estado, usufrui de direitos civis e políticos por este garantidos e desempenha os deveres que, nesta condição, lhe são atribuídos".

A respeito do cidadão e da cidadania, tem-se que "o primeiro compromisso ético dos cidadãos reside no cumprimento da lei. (...) A cidadania não se compõe apenas por um conjunto de direitos, mas também por uma série de deveres, dentre eles o de seguir as determinações legais e o de pagar impostos. É a chamada ética da legalidade. $\mathrm{O}$ compromisso ético das organizações não se esgota na obediência às leis, mas começa no respeito por esse 'mínimo ético'" (LAMBOY; RISEGATO; COIMBRA, 2018, p. 21).

Para Gentili e Alencar (2001, p. 87), “a cidadania deve ser pensada como um conjunto de valores e práticas cujo exercício não somente se fundamenta no reconhecimento formal dos direitos e deveres que a constituem na vida cotidiana". Isto porque apenas conceituação formal não se mostra suficiente, devendo haver, principalmente, a aplicação prática deste conceito. A cidadania implica reconhecimento e, especialmente, o cumprimento dos direitos e deveres dos cidadãos em sua relação com a sociedade, não estando restrita à esfera política.

Com base na noção atual mais difundida de cidadania, enquanto reconhecimento e cumprimento dos direitos e deveres do cidadão, ao transpor seu conceito para o mundo do trabalho, faz-se necessário atentar para seu caráter bilateral: direitos e deveres. Diante disso, é possível identificar que os comportamentos comumente denominados na literatura como cidadania organizacional não fazem referência aos direitos e deveres dos trabalhadores, mas sim aos comportamentos que estes ofertam para a organização por espontânea vontade e, a priori, sem esperar algo em troca.

Ao abordar apenas um lado dessa relação, referindo-se às ações espontâneas do colaborador para manutenção da efetividade organizacional, o conceito de cidadania organizacional amplamente adotado na literatura não se mostra em consonância com o real significado da palavra cidadania. Frente a esta constatação, Siqueira (1995) levantou brevemente o debate acerca desta inadequação, 
questionando a concepção de cidadania organizacional enquanto gestos altruísticos do trabalhador para com a organização

Como resultado, a autora sugeriu timidamente que a expressão "civismo nas organizações" seria mais adequada para designar tais comportamentos espontâneos, com base em sua etimologia. $\mathrm{O}$ termo civismo, do latim civis - cidadão -, significa "dedicação e fidelidade ao interesse público" (HOUAISS, 2001, p. 734), referindo-se ao compromisso do sujeito para com os interesses da comunidade à qual está vinculado, por meio de práticas cotidianas contribuem para o bem-estar coletivo. Nota-se que a transposição deste conceito para o ambiente organizacional mostra maior proximidade e consonância com as ações espontâneas dos colaboradores do que o conceito de cidadania que, por sua vez, possui um caráter bilateral, ao envolver direitos e deveres.

Um levantamento da literatura empírica nacional permitiu constatar que, apesar da importância do referido debate, não há uma institucionalização do uso do termo civismo nas organizações e o termo cidadania organizacional ainda é frequentemente a utilizado de forma equivocada (ZARIFE, 2016). Ainda, revisões da literatura brasileira tendem a desconsiderar as diferenças entre os construtos civismo e cidadania (i.e. CANTAL; BORGES-ANDRADE; PORTO, 2015; GOMES et al., 2014).

Um dos escassos esforços identificados na literatura para a institucionalização do uso de civismo nas organizações, em detrimento do uso de cidadania organizacional, foi realizado por Porto e Tamayo (2002, 2003, 2005). Estes pesquisadores desenvolveram a Escala de Civismo nas organizações (ECO), com a adoção do termo adequado, além de investigar sua relação com outros construtos.

Os poucos estudos que abordam a problemática civismo $\mathrm{x}$ cidadania organizacional costumam sinalizar a adequação do primeiro termo para abordar as ações espontâneas dos trabalhadores não formalmente reconhecidas pela organização, (SIQUEIRA, 1995; PORTO; TAMAYO, 2002, 2003, 2005; DIAS; OLIVEIRA, 2016). Todavia, não foi identificada na literatura a proposição de um conceito de cidadania organizacional condizente com a etimologia, o que pode constituir uma explicação plausível para a pouca adoção do termo civismo. Isto porque, indicar civismo nas organizações como mais 
pertinente para denominar os comportamentos espontâneos, mas não propor um "novo" e condizente significado para o termo cidadania organizacional pode indicar falta de consistência e/ou maturidade no debate, levando os pesquisadores a optar pelo termo mais tradicional. Diante desta lacuna, o segundo objetivo deste trabalho foi propor uma definição de cidadania organizacional condizente com a etimologia do vocábulo cidadania.

\section{Proposição de um novo Conceito de CidAdania ORGANIZACIONAL}

Uma instituição é um sistema público de regras que envolve cargos e posições e seus respectivos direitos e deveres. As regras possuem a função de especificar as ações permitidas ou proibidas e suas penalidades e defesas. Neste contexto, cada membro da instituição sabe o que as regras exigem dele e dos demais, e tem conhecimento de que os outros membros sabem o que é exigido dele (RAWLS, 1999).

As organizações podem ser entendidas como associações de indivíduos que agem, na maioria das vezes, de acordo com as normas de conduta da empresa. A importância destas normas reside especialmente em possibilitar que a organização cumpra seus objetivos e missões e que as pessoas realizem seus desejos e necessidades; sinalizando a importância de se investigar as percepções dos trabalhadores acerca do respeito a seus direitos e deveres.

Dentre outras metáforas, Gareth Morgan (2006) propôs uma visão de organização como sistemas de governo, realizando uma comparação entre os sistemas organizacionais e políticos. Neste caminho, é possível conceber que se um cidadão civil está subordinado às leis e regras do Estado, sendo detentor de direitos e deveres, numa analogia, a organização pode ser entendida como o Estado, e o trabalhador como o cidadão.

O cidadão organizacional, como membro de uma organização que possui normas de condutas, deve reconhecer seus direitos e deveres nesta relação, respeitando e cumprindo as normas instituídas e requerendo da organização o respeito aos seus direitos. Ser cidadão organizacional compreende, nesta perspectiva, o gozo dos direitos e deveres envolvidos na relação de trabalho com a organização. 
Outro elemento intimamente ligado à noção de cidadania é a coletividade. Pelas ideias de Rousseau (2018), o povo é constituído de pessoas conscientes de seu papel social e de que este papel deve ser desempenhado visando um bem comum. Logo, ser cidadão implica a transformação do sujeito numa parte de um todo maior.

O próprio Estado, tão presente nas definições de cidadania, representa o poder absoluto desta coletividade para a consecução do bem comum. Assim, a noção de coletividade também deve ser considerada na cidadania organizacional: o colaborador deve ter ciência do impacto de seu comportamento nos demais colaboradores e na organização como um todo, sendo incentivado a buscar o bem comum, por meio do exercício de seus direitos e deveres.

Partindo da perspectiva de análise etimológica da cidadania no contexto organizacional, baseada nos direitos e deveres do trabalhador em sua relação com a organização, este ensaio teórico propõe que cidadania organizacional seja concebida enquanto um conjunto de práticas fundamentado no reconhecimento e exercício dos direitos e deveres existentes na relação entre empregado e organização, visando à manutenção do bem-estar da coletividade organizacional. Nesta nova proposição, cidadãos organizacionais seriam aqueles que respeitam e apresentam padrões de comportamentos definidos pelo empregador que favoreçam o bem-estar coletivo (bom convívio com os demais) e a manutenção da organização (bem comum), incluindo a execução adequada de seus trabalhos, bem como têm seus direitos respeitados pela organização, como o recebimento de recompensas materiais e não materiais e a promoção de relacionamento positivos no trabalho.

Nas relações entre empregado e empregador, é possível identificar que os direitos dos trabalhadores e a participação sindical nas decisões organizacionais tendem a ser enfatizados em detrimento dos deveres dos mesmos (PORTO; TAMAYO, 2003). A Consolidação das Leis trabalhistas - CLT (BRASIL, 2019), importante marco regulador das relações de trabalho no Brasil, apresenta a maioria de seus artigos voltada para os direitos dos trabalhadores. Isto se deve às organizações, enquanto espaços sociais, possibilitarem a ocorrência de relações de poder desproporcionais: o empregador pode deter um poder descomunal em relação ao trabalhador, tor- 
nando fulcral o estabelecimento de medidas que proporcionem mais equilíbrio à relação.

Todavia, não somente de direitos do trabalhador é constituída a relação empregado-empregador. Mesmo frente à importância atribuída aos direitos do trabalhador, seus deveres não devem ser negligenciados. O artigo 482 da CLT (BRASIL, 2019) apresenta determinados comportamentos do empregado que justificariam sua demissão por justa causa, possibilitando identificar alguns deveres do trabalhador para com a organização. Desde que não ocasione prejuízo a outras obrigações, o empregado deve (BRASIL, 2019): (1) agir com honestidade; (2) ter bom comportamento; (3) ser assíduo e pontual; (4) não apresentar-se ao trabalho embriagado; (5) ter continência de conduta; (6) evitar a desídia - negligência, imprudência e imperícia; (7) guardar segredo profissional da empresa; (8) não praticar ato de indisciplina; (9) não praticar ato lesivo à honra e boa fama do empregador, superior ou terceiros - injúria, calúnia e difamação; (10) não praticar ofensas físicas, tentadas ou consumadas, contra o empregador, superior hierárquico ou terceiros, salvo em caso de legítima defesa, própria ou de outrem.

Não obstante a vigência da legislação, é frequente a identificação de casos de desrespeito aos direitos e deveres das partes envolvidas na relação, ocasionando uma ampla quantidade de processos judiciais e, por conseguinte, altos custos sociais (ZARIFE, 2016). Neste contexto, anualmente, Justiça do Trabalho recebe mais de três milhões de processos, com um cômputo de que a cada 100.000 pessoas, cerca de 1.800 ingressaram com uma ou mais ações ou recursos (BRASIL, 2017).

As discussões acerca dos direitos e deveres do trabalhador ganharam ainda mais visibilidade no Brasil em decorrência da reforma trabalhista realizada no ano de 2017. Neste período, muitas mudanças foram implementadas, tais quais a redução do tempo de intervalo de descanso e o fracionamento de férias anuais em até três períodos (BRASIL, 2019). Frente à proposição de um novo conceito para cidadania organizacional, bem como o descontentamento popular com as marcantes reduções dos direitos trabalhistas, é fulcral investigar as consequências da percepção de respeito aos direitos e deveres do trabalhador sobre o mesmo, sobre seu trabalho e sobre 
a organização à qual está vinculado, com vistas a disponibilizar informações que auxiliem para um maior entendimento deste processo relacional empregado-empregador.

\section{CONSIDERAÇõES FINAIS}

Conforme exposto, um dos grandes problemas da literatura sobre cidadania organizacional é a dificuldade de delimitação do construto que desde seus estudos iniciais esteve voltada às ações espontâneas dos colaboradores que promoveriam o bom funcionamento das organizações. A profusão e as limitações das definições propostas tiveram como consequência a dificuldade em delimitar dimensões consensualmente aceitas.

Na década de 1990, doze anos após a proposição formal do termo cidadania organizacional por Bateman e Organ (1983), críticas iniciais à pertinência da nomenclatura foram realizadas (SIQUEIRA, 1995). Este movimento culminou na proposição do termo civismo nas organizações como mais adequado para tratar dessas ações espontâneas e na ausência de uma proposição de conceito pertinente para a cidadania no contexto das organizações.

O presente ensaio teórico discutiu a adequação dos termos civismo e cidadania organizacional, mostrando concordância com a adoção do civismo para nomear os comportamentos espontâneos dos colaboradores. Isto porque, em sua essência, tal vocábulo denota compromisso com os interesses da comunidade à qual pertence; enquanto cidadania está etimologicamente ligada aos direitos e deveres do cidadão provenientes de sua relação com o Estado.

Diante da identificação da lacuna referente a uma definição de cidadania organizacional etimologicamente embasada, abarcando a perspectiva dos direitos e deveres do trabalhador, o presente trabalho propôs que o construto seja considerado um conjunto de práticas fundamentado no reconhecimento e exercício dos direitos e deveres existentes na relação entre empregado e organização, visando à manutenção do bem-estar da coletividade organizacional. Entendendo assim, que o cidadão organizacional é o trabalhador que possui seus diretos respeitados pela organização e que cumpre com seus deveres frente a ela.

Com a proposição de uma definição de cidadania organiza- 
cional condizente com o significado da palavra cidadania, este trabalho inaugura uma nova linha de investigação. Como agenda de pesquisa para um maior aprofundamento sobre a nova perspectiva de cidadania organizacional, sugere-se a realização de estudos que busquem investigar relações da percepção de respeito aos direitos e deveres do trabalhador com variáveis que venham a se configurar como antecedentes e consequentes do construto, tais quais qualidade de vida no trabalho, desempenho, bem-estar no trabalho, comprometimento organizacional, liderança e justiça organizacional. Ainda, diante da aparente sobreposição dos construtos reportada na literatura tradicional e com base no contraponto apresentado pela perspectiva etimológica, sugere-se, especialmente, a realização estudos que busquem evidências de validade discriminante entre os construtos de civismo nas organizações e cidadania organizacional.

\section{REFERÊNCIAS}

BARNARD, C. The function of the executive. Cambridge: Harvard University Press, 1938.

BATEMAN, T. S.; ORGAN, D. W. Job satisfaction and the good soldier: the relationship between affect and employee "citizenship". Academy of Management Journal, Nova Iorque, v. 26, n. 4, p. 587-595, dez. 1983.

BRASIL. Tribunal Superior do Trabalho. Coordenadoria de Estatística e Pesquisa do TST. Relatório geral da Justiça do Trabalho 2016. Brasília: CESTP, 2017. 246 p.

BRASIL. CLT e constituição federal. São Paulo: Saraiva, 2019.

BOTELHO, A.; SCHWARCZ, L. M. Introdução - Cidadania e direitos: aproximações e relações. In: BOTELHO, A.; SCHWARCZ, L. M. (Orgs.). Cidadania, um projeto em construção: minorias, justiça e direitos. São Paulo: Claro Enigma, 2012. p. 6-27.

CANTAL, C.; BORGES-ANDRADE, J. E.; PORTO, J. B. Cooperação, comportamentos proativos ou simplesmente cidadania organizacional? Uma revisão da produção nacional na área. Revista Psicologia Organizações e Trabalho, Brasília, v. 15, n. 3, p. 286-297, set. 2015.

COSTA, V. F.; ANDRADE, T. Comportamento de cidadania organizacional: caracterização da produção científica internacional no período de 2002 a 2012 . Revista de Administração Mackenzie, São Paulo, v. 16, n. 2, p. 45-71, mar./abr. 2015.

DIAS, F. R.; OLIVEIRA, A. F. Valores e confiança organizacionais: fatores determinantes nos comportamentos de civismo organizacional. Temas em Psicologia, Ribeirão Preto, v. 24, n. 3, p. 1087-1100, set. 2016.

GENTILI, P.; ALENCAR, C. Educar na esperança em tempos de desencanto. Petrópolis: Vozes, 2001.

GOMES, A. C. P. et al. Cidadania e cidadania organizacional: questões teóricas e conceituais 
que cercam a pesquisa na área. Estudos e Pesquisas em Psicologia, Rio de Janeiro, v. 14, n. 3, p. 711-731, jul./set. 2014.

GORCZEVSKI, C.; MARTIN, N. B. A necessária revisão do conceito de cidadania: movimentos sociais e novos protagonistas na esfera pública democrática. Santa Cruz do Sul: EDUNISC, 2011.

HOUAISS, A. Dicionário Houaiss da Língua Portuguesa. Rio de Janeiro: Objetiva, 2001.

KATZ, D.; KAHN, R. L. Psicologia social das organizações. São Paulo: Atlas, 1974.

LAMBOY, C. K.; RISEGATO, G. P.; COIMBRA, M. A. Introdução ao corporate compliance, ética e integridade. In: LAMBOY C. K. (Org.). Manual de compliance. São Paulo: Via Ética, 2018. p. 1-49.

LIMA, M. E.; MENEZES JUNIOR, A. S.; BRZEZINSKI, I. Cidadania: sentidos e significados. In: CONGRESSO NACIONAL DE EDUCAÇÃO, 13, 2017, Curitiba. Anais eletrônicos... Curitiba: EDUCERE, 2017. p. 2481-2494. Disponível em: https://educere.bruc.com.br/arquivo/ pdf2017/24065_12317.pdf Acesso em: 5 jul. 2019.

MONDAINI, M. O respeito aos direitos dos indivíduos. In: PINSKY, J.; PINSKY C. B. (Orgs.). História da cidadania. São Paulo: Contexto, 2013. p. 115-134.

MORGAN, G. (2006). Imagens da organização. 2. ed. São Paulo, SP: Atlas.

ORGAN, D. W. A reappraisal and reinterpretation of the satisfaction-causes-performance hypothesis. Academy of Management Review, Nova Iorque, v. 2, n. 1, p. 46-53, jan. 1977.

ORGAN, D. W. Organizational citizenship behavior: the good soldier syndrome. Lexington: Lexington Books, 1988.

ORGAN, D. W.; PODSAKOFF, P. M.; MACKENZIE, S. B. Organizational citizenship behavior: its nature, antecedents and consequences. Thousand Oaks: Sage, 2006.

PELLENZ, M. Metamorfoses da cidadania. Erechim: Editora Deviant, 2017.

PINSKY, J. Introdução. In PINSKY, J.; PINSKY, C. B. (Orgs.). História da cidadania. São Paulo: Contexto, 2013. p. 09-13.

PODSAKOFF, P. M; MACKENZIE, S. B.; PODSAKOFF, N. P. Organizational citizenship behavior: introduction and overview of the handbook. In: PODSAKOFF, P. M; MACKENZIE, S. B.; PODSAKOFF, N. P. (Orgs.). The Oxford handbook of organizational citizenship behavior. New York: Oxford University Press, 2018.

PODSAKOFF, P. M. et al. Transformational leader behaviors and their effects on followers' trust in leader, satisfaction, and organizational citizenship behaviors. The Leadership Quarterly, v. 1, n. 2, p. 107-142, abr. 1990.

PODSAKOFF, P. M. et al. Organizational citizenship behaviors: a critical review of the theoretical and empirical literature and suggestions for future research. Journal of Management, v. 26, n. 3, p. 513-563, mai. 2000.

PODSAKOFF, N. P. et al. Consequences of unit-level organizational citizenship behaviors: a review and recommendations for future research. Journal of Organizational Behavior, Oxford, v. 35, n. S1, p. S87-S119, jan. 2014. 
PORTO, J. B.; TAMAYO, A. Prioridades axiológicas e regiões brasileiras: preditores de civismo nas organizações. Revista Psicologia Organizações e Trabalho, Brasília, v. 2, n. 1, p. 31-61, jan./jun. 2002.

PORTO, J. B.; TAMAYO, A. Desenvolvimento e validação da escala de civismo nas organizações. Estudos de Psicologia, Natal, v. 8, n. 3, p. 393-402, set./dez. 2003.

PORTO, J. B.; TAMAYO, A. Valores organizacionais e civismo nas organizações. Revista de Administração Contemporânea, Curitiba, v. 9, n. 1, p. 35-52, jan./mar. 2005.

RAWLS, J. A theory of justice. Cambridge: Harvard University Press, 1999.

REZENDE FILHO, C. B.; CÂMARA NETO, I. A. A evolução do conceito de cidadania. Revista Ciências Humanas, v. 7, n. 2, p. 17-23, 2001.

ROBBINS, S. P.; JUDGE, T. A. Organizational behavior. Harlow: Pearson Education Limited, 2017.

ROUSSEAU, J. J. Do contrato social ou princípios do direito político. São Paulo: Edipro, 2018.

SILVA, B. Dicionário de ciências sociais. Rio de Janeiro: Editora da Fundação Getúlio Vargas, 1986.

SIQUEIRA, M. M. M. Antecedentes de comportamentos de cidadania organizacional: a análise de um modelo pós-cognitivo. Brasília, 1995. 239f. Tese (Doutorado) - Universidade de Brasília.

SMITH, C. A.; ORGAN, D. W.; NEAR, J. P. Organizational citizenship behavior: it's nature, and antecedents. Journal of Applied Psychology, v. 68, n. 4, p. 653-663, nov. 1983.

SPITZMULLER, M.; DYNE, L.; ILIES, R. Organizational citizenship behavior: a review and extension of its nomological network. In: BARLING, J.; COOPER, C. (Org.). The SAGE handbook of organizational behavior: Volume I - micro approaches. Londres: SAGE Publications, 2008. p. 106-124.

TINTI, J. A.; COSTA, L. V.; VIEIRA, A. M.; CAPPELlOZZA, A. O Impacto das Políticas e Práticas de Recursos Humanos Sobre os Comportamentos de Cidadania Organizacional. Brazilian Business Review, v. 14, n. 6, p. 636-653, 2017.

ZARIFE, P. S. Cidadania organizacional na perspectiva dos direitos e deveres e sua relação com justiça e estresse organizacional. Brasília, 2016. 186 f. Tese (Doutorado) - Instituto de Psicologia, Universidade de Brasília.

Recebido em: 6-8-2019

Aprovado em: 22-7-2021

Avaliado pelo sistema double blind review.

Disponível em http://mjs.metodista.br/index.php/roc 